\title{
La industria cultural de la nostalgia y la construcción de la memoria mediática ochentera en Monterrey
}

The cultural industry of nostalgia and the construction of the media memory of the 1980s in Monterrey

\author{
José Antonio Hernández-Gutiérrez \\ Tecnológico de Monterrey, México \\ dr.jose.hernandez@itesm.mx
}

\section{Forma de citar este artículo:}

Hernández-Gutiérrez, J. A. (2019). La industria cultural de la nostalgia y la construcción de la memoria mediática ochentera en Monterrey. RAEIC, Revista de la Asociación Española de Investigación de la Comunicación, vol 6, núm. 11, 224-245.

DOI: https://doi.org/10.24137/raeic.6.11.13

\section{Resumen:}

En Monterrey, México, existe una industria cultural de la nostalgia reflejada en el consumo mediático y de espectáculos en vivo. Con el objetivo de analizar el papel de la nostalgia musical en la construcción de identidades generacionales, se realizaron focus groups y entrevistas focalizadas con informantes clave. Encontramos que la nostalgia es un medio para llenar vacíos emocionales y afectivos, consecuencia de la posmodernidad.

Palabras clave: industria cultural, nostalgia cultural, memoria mediática, identidad generacional, ochenteros

RAEIC, Revista de la Asociación Española de Investigación de la Comunicación vol. 6, núm. 11 (2019), 224-245 


\begin{abstract}
:
In Monterrey, Mexico, there is a cultural nostalgia reflected in media and live shows consumption. To analyze the role of musical nostalgia in the construction of generational identities, focus groups and focused interviews with key informants were conducted. We find that nostalgia is a means to fill emotional and affective gaps, a consequence of postmodernity.
\end{abstract}

Keywords: cultural industry, cultural nostalgia, media memory, generational identity, 1980s generation

\title{
1. INTRODUCCIÓN
}

Las últimas dos décadas del siglo $\mathrm{XX}$ y la primera del $\mathrm{XXI}$ se caracterizaron por la búsqueda de modelos vanguardistas en las modas, las artes, el diseño, la publicidad y la cultura popular. Con esta tendencia se insinuaba que la sociedad posmoderna se caracterizaba por mirar exclusivamente hacia el futuro, símbolo de progreso, desarrollo y avances tecnológicos, y dejar atrás el pasado, que representa la tradición y el atraso ideológico y científico. Sin embargo, en el ámbito académico, pensadores como el escritor ruso Alexandr Solzhenitsyn, hacían notar que lo aparentemente novedoso tenía detrás una esencia nostálgica y mnemónica.

En 1993, Solzhenitsyn publicó en la revista New York Times Book Review el artículo denominado "The relentless cult of novelty and how it wrecked the century". En su colaboración, el autor advirtió que, si bien, tras el fin de la guerra fría comenzó a gestarse en todo el mundo una nueva generación de artistas jóvenes con propuestas frescas, ella no podía desprenderse de la "memoria de lo que vino antes. (Ya que) Ninguna obra nueva de arte llega a la existencia... sin un lazo orgánico con lo que se creó anteriormente" (p. 3). Por lo tanto, él concluye, el culto a la novedad que muchos artistas proclaman a través de un falso vanguardismo desde finales del siglo pasado, lejos de ser la representación simbólica del progreso occidental se convirtió en un 
intento para reflexionar acerca de los valores éticos y morales del proyecto de modernidad, debido a que en la nueva estructura social-posmodernidad- "No hay Dios, no hay verdad, el universo es caótico, todo es relativo" (Solzhenitsyn, 1993, p. 4).

Las diferentes industrias mediáticas y del entretenimiento mercantilizaron masivamente la memoria cultural de las últimas generaciones del siglo $\mathrm{XX}$, convirtiéndose en un negocio exitoso y fructífero. Ésta sería una manifestación de lo que Habermas denominó colonización del mundo de vida. En el segundo tomo de "Teoría de la acción comunicativa" (1981/1987) este sociólogo argumentó que una de las características que adopta la racionalidad sistémica durante el capitalismo tardío es incorporarse en la esfera privada, permitiendo la monetarización y la burocratización de la vida cotidiana, a través de la modificación de las formas de vida y las experiencias estético-expresivas, vaciándolas de contenido, especialmente porque los sistemas expertos (el poder y el dinero) lograron incorporarse en la vida de los sujetos, imponiéndoles lo que deben consumir. En este sentido, (lo que denominamos) industria cultural de la nostalgia pone a disposición de los nostálgicos un catálogo limitado de bienes simbólicos, de entre los cuales ellos tienen que "elegir" con la intención de satisfacer sus necesidades afectivo-emocionales.

Empero, así como la comercialización de la nostalgia ha sido muy rentable para las empresas, existen suficientes individuos nostálgicos que consumen esos bienes culturales con la intención de satisfacer alguna necesidad emocional o afectiva. El sujeto posmoderno (Hall, 1992/2003, 1996) sabe muy bien que es imposible regresar al pasado, pero sí puede estar en contacto con entes físicos y culturales que le evoquen las anécdotas más felices de su vida, con la intención de hacer más llevaderos el presente y el futuro.

A pesar de lo anterior, la nostalgia como fenómeno social no es algo nuevo. En algunas épocas, por ejemplo, las sociedades expresaban un culto o veneración por sus héroes nacionales y por su pasado histórico; pero, en la actualidad, la nostalgia ha abandonado los espacios intelectuales, políticos y académicos para ubicarse en ámbitos tan 
cotidianos como los medios de comunicación, la cultura popular-masiva y el ocio. Entonces tanto la cultura popular como la memoria mediática, como elemento particular de la memoria colectiva, se encuentran presentes en el proceso de construcción, reconstrucción y consolidación de la identidad cultural de los individuos y las comunidades contemporáneas (Berruga, 2015).

En especial, en el consumo y apropiación de la música popular es posible observar esta característica, dado el carácter emocional que tiene la participación de su audiencia cuando siente la música o recuerda alguna experiencia de vida al escuchar alguna canción que le es significativa (Lull, 1992; De la Peza, 2001, 2014; Echeverría y Karam, 2014). Hay canciones que desde hace varias décadas no han dejado de escucharse por la radio, debido a que alguien sigue solicitándolas.

Desde una perspectiva más sociológica y menos económica, la nostalgia cultural no obedece a la moda ni a las leyes del mercado, sino a una necesidad social y cultural de no perder de vista los orígenes de nuestra identidad en un mundo estresante donde constantemente nos vemos en medio de eventos que nos orillan a tomar riesgos (Beck, 1998) y a sentirnos inseguros, en incertidumbre.

En lo particular, la investigación que antecede a este artículo surgió a partir de que el investigador observó que una buena parte de la oferta cultural y mediática está vinculada con la nostalgia. En los medios locales, nacionales e internacionales hay espacios dedicados a la retransmisión de este tipo de objetos culturales. Asimismo, algunas firmas disqueras han resurgido con el interés de remasterizar y comercializar en $C D$ y en versión digital los principales álbumes de su catálogo; es decir, grabaciones de artistas que fueron muy populares en décadas anteriores indistintamente del género musical que interpretaban; además, las industrias cinematográfica y televisiva están digitalizando una gran cantidad de películas y series que fueron muy populares hace apenas algunas décadas -llamadas, comúnmente, "clásicas"-, para ponerlas a disposición de la audiencia en DVD y en formato digital. Muchos de estos discos (o colecciones de discos) y DVD se encuentran "de paso" en la zona de cajas de cualquier 
centro comercial, por lo que su distribución y venta llegan a tener gran éxito. Incluso, se venden a precios muy accesibles dentro de tiendas virtuales como Amazon o Ebay.

Específicamente, en la ciudad de Monterrey, Nuevo León (México), las industrias culturales tienen una oferta más o menos amplia de música popular retro, de tal forma que se puede hablar de la existencia de una cultura mediática de la nostalgia entre la población regiomontana (como se denomina a sí misma), reflejada en el consumo local de radio, televisión y espectáculos en vivo. En el dial radiofónico, la cuarta parte de todas las estaciones y dieciséis programas de otras emisoras -incluyendo las de corte universitario- son especializados en música generacional.

Las once estaciones identificadas se clasifican en varios géneros: 1) música regional, la cual incluye canciones rancheras, norteñas, polkas, tejanas y cumbias norteñas, así como lo más representativo de los orígenes del movimiento grupero; 2) boleros, interpretados por tríos, orquestas y solistas; 3) éxitos en español, especialmente baladas, pop y rock de los años setenta, ochenta y noventa, y 4) hits en inglés, cuyo catálogo se integra por rock y pop de los sesenta a los noventa, así como música disco de los setenta y ochenta. Por su parte, la televisión local también destina cierto tiempo a la nostalgia musical ofertando tres programas con videos musicales retro y cuatro con música en vivo.

Estas emisiones incluyen reportajes y entrevistas relacionados con temas de interés para los nostálgicos. Por último, en varios sitios del área metropolitana regiomontana, con frecuencia se organizan conciertos con bandas y solistas que estuvieron de moda entre los adolescentes y jóvenes en la década de los ochenta; así mismo, en algunos bares, clubes y discotecas se llevan a cabo bailes o fiestas temáticas en torno a la época en cuestión; es más, sobresale que este tipo de eventos no están destinados a un solo tipo de público, sino que se satisfacen las necesidades emotivas y afectivas tanto de quienes prefieren escuchar rock o pop, como de los que eligen las baladas o la música regional y tropical. 
Habiendo identificado a la nostalgia como un fenómeno socio-cultural de la actualidad, se buscó una explicación desde una óptica más analítica. En consecuencia, se obtuvo el siguiente problema de investigación: Ante las nuevas condiciones económicas y sociales, las industrias culturales posmodernas intentan cooptar las necesidades estéticas y emocionales de los individuos para producir, reproducir y distribuir bienes afectivos; entre los que se encuentra la música popular que evoca los recuerdos de las generaciones. Así que, el nostálgico posmoderno orillado, en gran medida, por la incertidumbre que le causa el sistema, en un proceso de estetización y reflexividad de su vida cotidiana se apropia los bienes culturales que con el paso de la moda fueron vaciados de sentido y desprovistos de carga afectiva, no por un sentido reaccionario de estacionarse en el tiempo, sino para re-llenarlos (re-significarlos) y darles un nuevo uso: el suyo, y ya no el propuesto originalmente por la industria.

Por lo anterior se discurre que, ante la influencia que ejercen las industrias culturales sobre las audiencias al ofrecerles catálogos limitados, los individuos buscan espacios simbólicos que les permitan desarrollar su creatividad. Esto lleva a concluir que existe entre estos dos actores, las industrias y los individuos, una pugna por la significación de los bienes musicales, pues mientras las primeras imponen un sentido utilitarista, ligado al beneficio económico, que se vacía con el paso de la moda, los segundos le atribuyen un nuevo significado, motivado por la inseguridad ontológica generada por la nueva estructura social y relacionado con sus experiencias y emociones personales y colectivas; es decir, generacionales.

\section{MÉTODO}

Para efectuar esta investigación, se optó por diseñar una metodología que permitiera tener un acercamiento con los actores, dado que la intención era conocer sus opiniones, sus formas de pensar y sus intereses personales, además de analizar los sentidos y significados que los sujetos le dan a su mundo-de-vida como resultado de las experiencias compartidas y las interacciones cotidianas; por lo tanto, se decidió que lo pertinente sería una aproximación cualitativa. Específicamente, el investigador decidió 
aplicar dos técnicas cualitativas para recoger información: grupo de enfoque focus group) y entrevista focalizada con informante clave.

Durante la fase exploratoria del trabajo empírico, en primer lugar, el investigador buscó una estrategia para conseguir el contacto personal y directo con miembros de la generación ochentera que radican en el área metropolitana de la ciudad de Monterrey, Nuevo León. Para lograr esto, se realizó un mapeo del fenómeno con el interés de ubicar los lugares y los medios donde se consume música de los ochentas; entonces, aparte de las estaciones de radio y los programas de televisión donde se difunde música de esta generación, se inquirió información sobre bares, centros de espectáculos, conciertos y salones de baile especializados en los géneros más populares: a) pop en inglés y en español, b) rock en inglés y en español, y c) música regional-popular. Así mismo, se solicitó el acceso a blogs (foros de discusión en internet) donde personas pertenecientes a la población sujeto de este estudio usualmente intercambian ideas nostálgicas acerca de sus gustos y preferencias mediáticas, en general, y musicales, en particular.

En esta fase preliminar, después de haberse elaborado el mapa, se aplicó muestreo por bola de nieve con el fin de contactar entre 28 y 35 informantes. Originalmente se pensó únicamente en la realización de seis sesiones de focus group, más una prueba piloto; no obstante, dado que a lo largo de la bola de nieve se tuvo acercamiento directo con informantes clave, que podrían aportar información importante, se decidió entrevistarlos de forma individual. Cuando se habla de informantes clave se aluden los individuos que, por sus conocimientos, aptitudes, influencia o experiencias tienen una notable posición dentro del fenómeno que se investiga. Inclusive, los comentarios aportados por estas personas complementaron la información recabada por medio de los focus groups.

Finalmente, se realizaron seis grupos focales (se excluye la prueba piloto), y además seis entrevistas focalizadas con informantes clave.

Metodológicamente se tomó en cuenta la población perteneciente a los niveles socioeconómicos medio y medio alto, debido a que el $60 \%$ de la población total del 
estado de Nuevo León pertenece a este fragmento (según datos del Centro de Investigaciones Económicas de la Universidad Autónoma de Nuevo León (García, 2014), convirtiéndose en el público-consumidor más amplio de cultura popular en esta misma entidad, incluso $17 \%$ por encima de la media nacional.

Por último, en el análisis del material recaudado se hace mención únicamente del pseudónimo asignado a cada uno de los participantes acompañado de su año de nacimiento, por ejemplo, Alejandro (1969). Cabe mencionar que en este artículo no se incluyeron todas las intervenciones de los participantes. Únicamente se eligieron algunos fragmentos representativos.

\section{OCHENTEROS REGIOS: CONSTRUCCIÓN DISCURSIVA DE UN NOSOTROS}

El punto de partida de este estudio es la idea de que una generación es un conjunto de personas que comparten un cierto rango de edades, así como un determinado contexto espacio-temporal y socio-cultural (Eyerman y Turner, 1998; Corsten, 1999; Ghiardo, 2004). Esto habla de que los sujetos coetáneos de alguna manera son co-partícipes de ciertos eventos críticos o significativos, sean estos presenciales o no, que en menor o mayor medida les hace sentir un grado de identificación entre sí. Es más, ocurre así, aunque ellos se encuentren colocados en diferentes posiciones económicas, políticas, sociales o culturales, como usualmente pasa al interior de las distintas comunidades que constituyen las sociedades contemporáneas.

Para continuar con lo que se dijo líneas arriba, cabe hacer alusión de que, según Stuart Hall (1996), la versión posmoderna de la identidad implica inestabilidad y diversidad, pues, aun cuando haya identificación o reconocimiento entre los sujetos que forman parte de una comunidad, debido a los rasgos sociales y culturales compartidos, la identidad colectiva no necesariamente implica uniformidad entre ellos; más bien, debe considerarse que, de antemano, hay diferencias ligadas a la trayectoria biográfica que cada quien recorre a lo largo de su vida. Consiguientemente, las identidades generacionales posmodernas no deben entenderse como resultados, sino como procesos. En otras palabras, no son proyectos coherentes, acabados, ni cerrados; más 
bien, en el día a día los sujetos involucrados los construyen de manera heterogénea y fragmentaria. Por lo anterior es que Hall entiende que la modernidad tardía es un intento de liberación, en el cual el sujeto posmoderno -como él mismo le denomina- no tiene miedo a ser diferente a los demás, ni a dejar de ser lo que es ahora, como solía suceder con las identidades de la modernidad organizada.

De acuerdo con lo anterior, consideramos que los ochenteros regios no tienen una identidad; es decir, quienes nacieron entre 1961 y 1981 (Howe y Strauss, 1991) y que radican en el área metropolitana de Monterrey, de forma permanente e involuntaria participan en la construcción de su identidad, pues no es posible afirmar que todos piensan, sienten y actúan de la misma forma, sin distinciones sociales y/o culturales de por medio.

Antes que nada, los ochenteros se perciben a sí mismos como una generación de jóvenes divertidos pero inocentes, que no estuvieron expuestos a todos los riesgos a los que se están enfrentando las nuevas generaciones, las de sus hijos; así mismo, en el discurso se nota la presencia de un sentimiento de solidaridad y de pertenencia a un grupo social, basado en elementos lúdicos, oníricos y afectivos. En una de las sesiones de focus group, Alejandro (1969) definió a los ochenteros de la siguiente manera:

Los jóvenes en los ochentas éramos divertidos, jugadores, sin preocupaciones. Acostumbrabas a juntarte en casas de amigos a escuchar música, jugar futbol o ir a las kermeses de la Iglesia del Rosario -Colonia Roma, Monterrey- y en San Juan Bosco Colonia Alta Vista, Monterrey-.

En otro ejemplo, Axel (1971) afirmó que se casó básicamente por la presión social, debido a que estaba soltero teniendo treinta y tres años. A él le costó mucho trabajo decidirse a formar un matrimonio, sobre todo porque eso le significaba dejar de tener novias sin las responsabilidades legales que adquieren los miembros de la unión conyugal. Para Axel, lo ideal sería seguir soltero durante toda su vida y trabajar exclusivamente para adquirir las cosas que usualmente les gusta a los adolescentes, sin verse en la necesidad de limitar sus gastos por causa de las obligaciones familiares. 
Según este respondiente, una de las características de los ochenteros es el "Síndrome de Peter Pan" (Kiley, 1983).

Todos los juguetes que no tuve de niño, yo me los quise comprar de (adulto). Compré muchos cómics. Yo compré muchos cómics en los ochentas, y volví a comprar cómics otra vez... Y todos los discos que no tuviste en los ochentas también, lo compras también en $C D$, y lo tienes en cassette y en LP y en CD, y en MP3, ¿pa'qué, hombre?... Yo creo que fui parte de los que sufrimos el síndrome de Peter Pan, de que "no quiero crecer", "quiero seguir haciendo esto toda mi vida".

\section{MEMORIA COLECTIVA}

Ya que hemos visto que las generaciones a través de la narrativa marcan rasgos simbólico-discursivos que las autodefinen, pasemos a un segundo momento ligado a los recuerdos que son trascendentes o relevantes para los miembros de esa comunidad. Consideramos importante este aspecto, dado que el sentido de pertenencia a un grupo social se refuerza cuando sus miembros se sienten ligados simbólica y afectivamente a un pasado compartido.

Sin embargo, es manifiesto que cuando las generaciones posmodernas hablan de su pasado colectivo no necesariamente evocan los grandes acontecimientos de interés sociopolítico e histórico, sino que usualmente hacen mención de emotivas, placenteras o lúdicas, ligadas en muchas ocasiones a la vida cotidiana de cada individuo o del grupo al que pertenece.

Siguiendo con la misma discusión, es importante distinguir que la historia es secular, analítica e intelectual, mientras que la memoria es afectiva, emotiva y abierta; la primera es universal, perenne y nadie tiene derecho a poseerla, la segunda es múltiple localizada y pertenece a cada una de las comunidades mnemónicas (Zerubavel, 1996, 2003) y a todas las personas que forman parte de ellas. En consecuencia, la historia siempre está encadenada a las continuidades temporales, a las progresiones y relaciones entre las 
cosas; en cambio, la memoria se encuentra depositada en espacios, gestos, imágenes y objetos.

De acuerdo con lo anterior, las generaciones posmodernas son archivísticas, museísticas, pues los sujetos han mostrado una especial dependencia respecto a los vestigios, no únicamente los de tipo material sino también los simbólicos. Les encanta preservar todo lo que para ellos sea emotivo y placentero. Por consiguiente, hoy en día los bienes culturales toman el lugar de esos sitios de la memoria de los que habla Pierre Nora (1989), pues en ellos se encuentran depositadas las evocaciones y las experiencias colectivas. En seguida se muestran fragmentos discursivos que ayudan a comprender lo anterior.

Recuerdo como relacionaba " $x$ " canción a lo que vivía en esos momentos, por ejemplo, me acuerdo de una canción que se llama "Hungry Eyes", no recuerdo el grupo -Eric Carmen-, pero esa canción sonaba bastante en la radio cuando andaba con una chica que tenía unos ojos hermosos... Además, recuerdo que nos juntábamos el grupo de amigos en casa de alguno de nosotros para escuchar algún disco que hayamos comprado, o ganado en las estaciones de radio, y la clásica grabada del disco poniendo la grabadora pegada a uno de los bafles y haciendo silencio lo más posible para que nos saliera bien el cassette-ríe-. iQué tiempos aquellos! (Anselmo, 1967)

Al respecto, se puede agregar que el historiador Jan Assmann (1988/1995) afirma que culturalmente existe una memoria comunicativa o cotidiana, que consiste en el cúmulo de recuerdos que tienen que ver directamente con las vivencias o experiencias de todas las personas. Lo esencial en este tipo de remembranzas es que siempre están situadas en un ambiente cultural específico, es decir, en un determinado contexto espaciotemporal.

Es más, en su participación varios informantes sacaron a colación sus reuniones de amigos, en las cuales siempre están presentes los recuerdos, las experiencias y las anécdotas. 
A mí sí me gusta, por ejemplo, hacer reuniones con amigas que, incluso, tengo una para el 20 de abril. Vamos a pedir permiso en la primaria, de que nos presten el este -con las manos simula tener un banderín escolar-y poner fotos de cuando estábamos chiquitos y todo ese tipo de cosas. Yo sí acostumbro mucho, este, recordar. Vamos a poner las fotos y uno que otro que tenía video, dije: "yo me acordaba que existían... así estaría la camarota -dimensiona con las manos-, ¿verdad?" -ríe-... Es cierto, somos bastantes los de los ochentas que estamos así, añoramos constantemente eso (...). Nuestra familia la conoce porque uno se la está explicando, pero pues si hubiera otra manera de que se pudiera que se pusieran los juegos y caricaturas y todo, también. Ayudaría mucho porque todo... yo siento que todo... muy bonita época (Aurora, 1974).

\section{NOSTALGIA MEDIÁTICO-CULTURAL Y MUSICAL}

Como hemos revisado en este artículo, las memorias colectivas, al igual que las identidades posmodernas, son múltiples e inacabadas. Cada generación reconstruye su pasado de una manera fragmentada, pues cada sub-generación vive y experimenta su posición en la realidad social dependiendo de las condiciones contextuales en las que se desenvuelve. La reconstrucción que, de su pasado, hacen las generaciones posmodernas tiene un vínculo directo con la relación existente entre los sujetos y cultura mediáticopopular.

Es decir, comúnmente las experiencias de vida tienen una especial asociación emotiva con lo que se consume a través de los medios electrónicos de comunicación. Partiendo de este asunto, advertimos que la nostalgia es un elemento característico en la reconstrucción que cada generación hace de su propio pasado, pues por lo regular los momentos más significativos de la vida de los individuos están presentes en los recuerdos que tienen de sus vivencias de niño, adolescente o adulto joven. Para el sociólogo Fred Davis $(1977,1979,1981)$, la nostalgia es una emoción social que actúa como un resguardo que experimenta el yo contemporáneo contra la inseguridad y la inestabilidad emocional, así como también contra la pérdida de confianza y credibilidad 
respecto a las instituciones tradicionales, específicamente el Estado, el sistema financiero global, los medios de procuración de justicia, etc.

En los siguientes fragmentos se puede leer que el consumo de música generacional entre los ochenteros regios es de gran importancia, principalmente porque ella es depositaria de emociones, experiencias y recuerdos que, juntos, le dan sentido y significado a la vida colectiva de toda la generación. Aquí subrayamos que, dado el carácter social de la música popular, ésta se ha convertido en uno de los agentes de fortalecimiento de las relaciones grupales, sobre todo porque las emociones y los sentimientos que se estimulan cuando se le escucha -alegría, tristeza, amor, odio, etc.se comparten y transmiten con quienes se tienen aspectos comunes, es decir, no únicamente la edad, sino también elementos contextuales y socio-culturales bien localizados. Por lo tanto, la música es un estimulante emocional que sensualmente actúa de forma directa en el estado afectivo de los individuos que la escuchan, sobre todo cuando ellos asocian la melodía o la letra de cierta canción, o algún cantante o grupo, a un determinado evento personal o grupal. En consecuencia, el disfrute nostálgico de la música está asociado simbólicamente con vivencias concretas, experiencias de vida, agradables o no (De la Peza, 2001).

\footnotetext{
"Jump" de Van Halen era básica para el entrenamiento de Soccer en la secundaria, "Dreams" también. Obvio, la parte romántica de bailar pegaditas con cualquier intento de ligue no sería lo mismo sin las baladas de REO (Speedwagon) o Journey. Personalmente siempre he sido fan de las letras, la música y el mensaje vanguardista de las canciones de Mecano y "La fuerza del destino" fue la canción que bailé el día de mi boda. (Antonio, 1969)
}

Isaías (1967), uno de los informantes clave, es un locutor de radio local que tiene un programa dedicado a la "nostalgia grupera" (grupero es el término popular con el que se conoce al género regional mexicano). Él nos compartió un pasaje de su vida personal vinculada con la música: 
Cuando era pequeño yo boleaba zapatos en la "Alameda Mariano Escobedo" (centro de Monterrey), precisamente, y luego vendía chicles, ahí le buscaba la vida. Llegamos muy pobres de Linares (Nuevo León) y nos buscábamos la vida entre mi hermano, un poco mayor que yo, y un servidor. Entonces, yo escuchaba mucha música, porque era la época de las grabadoras, eran los ochentas, finales de los setentas, principios de los ochentas, era la época de las radiograbadoras, cuando todos traían su radiograbadora y competían para ver cuál tenía más foquitos y más cosas por el estilo, o la más grande... yo escuchaba mucha música con ellos, porque cuando boleaba ahí tenían su grabadora, todo el mundo escuchaba música, en ese entonces todo el mundo oía música.

Había grupitos en "la alameda", porque yo boleaba ahí, había grupitos de cinco o seis muchachas que todas traían grabadora, todas... oían sus rolas, y oía música con ellas, o boleaba y ahí tenía la grabadora y oía música, música, música, música. Siempre mi vida fue oír música, y por eso conozco de grupos, porque eran "Los tremendos sepultureros", era Rigo Tovar, era "Los terrícolas", eran los grupos favoritos de la raza en ese entonces. Más que anécdota es de que crecí con esa música y a mí, esta música me remonta a esos tiempos de trabajo, de lucha, de esfuerzo, de salir día con día a ganarse el pan con el sudor de la frente.

Como se advierte en las intervenciones previas, las generaciones se fragmentan principalmente desde el ámbito socio-económico, y esto hace que las historias generacionales también se diversifiquen; es más, esa diferenciación se cristaliza en la preferencia que cada consumidor tiene de la música que escucha: por un lado, están quienes privilegian la música en español, y por otro, a quienes les gusta más la música en inglés.

Con base en lo anterior, es en las experiencias de vida y en el consumo cultural donde logramos encontrar las diferencias existentes entre unos y otros miembros de una misma generación. De tal forma que sería incorrecto decir que todos los jóvenes crecen con las mismas oportunidades o con vivencias más o menos idénticas. Por ello, la 
nostalgia mediático-cultural se ha convertido, en los años recientes, en depositaria de historias de vida diferentes y, muchas veces, contradictorias.

Cabe decir que, de acuerdo con los comentarios de la mayoría de los entrevistados y de los asistentes a los focus groups, los ochenteros regios forman parte de una generación sumamente musical, con una gran diversidad de consumo. Es más, varios afirmaron que es muy difícil desprenderse de su música: no han dejado de escucharla, la siguen consumiendo en su vida cotidiana (Stipp, 1990). De hecho, según ellos, cuando la escuchan aparte de recordar momentos importantes de su vida, sienten que rejuvenecen y que se recargan de energía positiva para enfrentar o resistir todos los problemas y responsabilidades que se tienen en el día a día (Lull, 1985):

De repente sí compro música de los ochentas, básicamente de canciones que siempre quise tener y no las tenía, o las tengo en esos cassettes que te comentaba... Sí la sigo oyendo porque me inspira, no hay nada mejor que cargarse de energía en la mañana oyendo un buen Heavy Metal. Como que te rejuveneces oyendo " $\mathrm{x}$ " $\mathrm{o}$ " $\mathrm{y}$ " canciones, es sentirte vivo $\mathrm{y}$ decir: "vengan todas las broncas del día de hoy, estoy listo para todo, estoy lleno de ánimos y energía para todo". Es sentirte vivo y lleno de energía. (Anselmo, 1967)

Son parte de tu vida, puede manejarlas la gente como motivaciones, como pilas, como para recargar baterías o detalles de... así, que a lo mejor ahorita el nivel de vida por las responsabilidades que tenemos, pos' es muy rápido y es muy... iay, se te va el tiempo!... iClaro!, tienes los pies en la tierra, pero darte tiempo para ti, a lo mejor, para agarrar la pila que ocupas, para andar entre el tráfico y que se te atraviesan, o que, a lo mejor vas caminando y alguien te empujó; cosas así... (Astrid, 1974)

De acuerdo con los ochenteros regios, además de ser un elemento clave en la construcción de las identificaciones y de cumplir socialmente un papel de depositaria de los recuerdos y las vivencias de cada persona que le otorga un significado especial, la música es lo único que permanece con el tiempo. 


\section{CULTURA RETRO}

Para Elizabeth Guffey (2006), lo retro permite reflexionar en torno a las ideas, los límites y la moralidad del pasado moderno, al cual también le denomina pasado reciente. Esta historiadora norteamericana del arte advierte que cuando se habla de la cultura retro se alude a algo más que a la recuperación de las "viejas modas" o de los "artículos obsoletos". Realmente, el término retro sugiere un cambio de actitud o una nueva relación popular con el pasado, pues, lejos de remitirse a la recuperación de las viejas tradiciones, se enfoca al pasado reciente, sobre todo porque la tendencia retro hace que resalten el arte y la cultura populares contemporáneos. Es más, lo retro no debe ser considerado una mirada nostálgica hacia el pasado pre-industrial de las sociedades actuales, por ello se le vincula con el consumo cultural-mediático.

A propósito de este asunto, es oportuno aceptar que con las modas retro muchas empresas han logrado empaquetar el pasado transformándolo en artículo de aparador; empero, la cultura retro también se ha convertido en una nueva forma con la cual los miembros de la sociedad cuentan su propia historia, sin depender necesariamente de las versiones oficiales. Sobre este asunto, elegimos un par de unidades discursivas:

El informante Abel (1973) afirma que, cada vez que escucha la música de su generación, se siente más seguro o tranquilo que como lo es habitualmente, sobre todo ante el actual clima de inseguridad, crisis económica y violencia por el que atraviesa el estado de Nuevo León. En este caso, dice, la música es el medio que los sujetos tienen a su alcance para revivir o recordar el escenario histórico en el que los regiomontanos vivían alejados de los actuales riesgos económicos y sociales.

Yo creo que mucho tiene que ver ahora el entorno social y económico en Monterrey, ya que inconsciente o conscientemente añoramos tener la tranquilidad de los días que todo era más relajado en la ciudad, y esa música nos transporta sin boleto de entrada o "cover" a esos días. 
Para Angélica (1963), psicóloga y madre de familia, es importante reflexionar acerca de su vida pretérita, pues ese tipo de ejercicios le da madurez personal y profesional, porque reconoce los errores que cometió en los años pasados.

Esos años forjaron lo que soy actualmente, aparte de que recordar es vivir. Las experiencias, como aciertos y errores, nos sirven para aplicarlo en nuestros hijos y compartirlo con ellos... Los jóvenes ahora son más autosuficientes, son más exigentes en cuanto a las comodidades en las que quieren vivir. Además, como resultado de lo que mencionaba anteriormente de reprimirlos menos y dejarlos ser, ahora son menos tolerantes con los demás, causando así relaciones interpersonales más conflictivas en ambientes escolares, laborales, y en ambientes familiares, viéndose esto reflejado el alto índice de hogares disfuncionales que hay actualmente.

En suma, la cultura retro no está fundamentada exclusivamente en el reciclaje cultural, sino que, también se ha desarrollado como una mirada crítica, irónica y reflexiva del pasado reciente. Es una respuesta social que está emergiendo a raíz de la insatisfacción social ante las consecuencias de la modernidad industrial (Grainge, 2002; Guffey, 2006; Giddens, 1990). Es un medio para contrarrestar el sentimiento de pérdida de confianza y de inseguridad ontológica (Giddens, 1991/2000) que representa el futuro incierto.

\section{CONCLUSIONES}

En sus propias palabras, los ochenteros regios se autodefinen como una generación divertida, solidaria e inocente. Quienes fueron niños durante los ochentas refieren entretenerse en la calle con juegos colectivos como salir en grupo a pasear en bicicleta por las calles y los parques de las colonias donde vivían. Además, solían reunirse con sus amigos en la casa de alguno de ellos para escuchar música, ver videos musicales, aprovechando la instalación masiva de antenas parabólicas que en aquella década se presentó en la capital nuevoleonesa, y para jugar futbol o videojuegos; pero, también, solían ir a centros de esparcimiento, como los cines, los patinaderos, los salones de fiesta, las discotecas y los restaurantes de pizzas y hamburguesas. 
Esa necesidad de grupo que sentían los ochenteros, se basaba en elementos afectivos, así como en los valores de amistad, respeto y solidaridad, pues para ellos la vida no se limitaba exclusivamente al juego y al esparcimiento. Así mismo, en el desarrollo tanto de las entrevistas como de las sesiones de grupo, fue notorio que en ningún caso se señaló que la diversión al aire libre durante la década de los ochentas fuera riesgosa o peligrosa, como se le califica hoy en día. Antes bien, los miembros de la generación ochentera advierten que la calle no era un simple sitio recreativo, sino que, más que nada, era su espacio de libertad. Los niños y jóvenes ochenteros del área metropolitana de Monterrey vivían y convivían en un ambiente de tranquilidad y seguridad.

Hay que recalcar que, en general, los participantes apuntaron que para los jóvenes de su generación era muy importante la convivencia y la diversión en grupo, a diferencia de los niños y jóvenes de hoy, quienes privilegian entretenerse dentro de sus habitaciones, haciendo uso de las más recientes tecnologías informáticas y lúdicas, lo cual da cuenta de un marcado individualismo y de unas relaciones sociales demasiado cerradas. De hecho, la hiper-tecnologización de la vida cotidiana y la psicosis colectiva, producto de la inseguridad social, establecieron las condiciones para que la actual generación de niños y jóvenes mantengan más amistades virtuales que presenciales, dejando entrever que para estos no es tan importante la cercanía geográfica ni el contacto físico al momento de entablar una nueva relación amistosa o sentimental.

En otro orden de ideas, los miembros de la generación de los ochentas declararon sentirse ligados simbólica y afectivamente a un pasado comunitario, en donde convergen sus experiencias emotivas y placenteras. Concretamente, los ochenteros regios sienten nostalgia por sus experiencias de vida, más que por los grandes acontecimientos de la historia. Esto se evidencia discursivamente con el hecho de que sus referentes contextuales no son las instituciones gubernamentales o económicas, ni las autoridades políticas o eclesiásticas, sino las anécdotas que despiertan emociones y sentimientos tanto individuales como de forma grupal. 
Sobre este asunto, cabe hacer mención que una parte importante de los recuerdos que integran la memoria colectiva de nuestros sujetos de estudio giran en torno al consumo de bienes culturales o mediáticos generacionalmente significativos. En particular, la música popular-masiva juega un rol muy importante en este proceso, ya que los informantes le otorgan una función sustancial como depositaria de evocaciones y experiencias. No obstante, concluimos que, al menos para nuestros sujetos de estudio, no existe una memoria generacional monolítica y heterogénea, sino varias memorias sub-generacionales, contrarias, superpuestas y complementarias.

Por otro lado, vale recordar que la nostalgia es una emoción social que dota de seguridad y confianza a los individuos y a las comunidades, de cara a la inseguridad y la inestabilidad emocional que heredaron las instituciones tradicionales. Pero, a pesar de esto, el sujeto nostálgico no necesariamente se resiste a los cambios y transformaciones experimentados por la sociedad actual, sino que revalora y reinterpreta -a veces irónicamente- su pasado reciente.

Si bien los ochenteros regios -a excepción de uno de los informantes- recuerdan con nostalgia y emoción la década de su niñez y juventud, en ninguna intervención manifestaron querer "regresar a casa", es decir, al momento en que se sentían resguardados por la seguridad ontológica y por la confianza que sentían respecto a, prácticamente, todos los sectores de la sociedad. Los participantes recurrentemente hicieron comparaciones de su década respecto al momento actual, no porque deseaban regresar a esa época o porque quisieran que las condiciones de la realidad actual sean como las de ese entonces, sino que, a través de este ejercicio, plantean estrategias que les permitan afrontar los inéditos riesgos sociales.

Los ochentas es una década muy significativa para los informantes de este estudio, y ellos saben bien que nunca volverá, debido a que las instituciones y estructuras de la sociedad han cambiado considerablemente y que los sujetos deben adaptarse a las nuevas condiciones de la realidad social. Así, advertimos que la nostalgia posmoderna 
es la emoción colectiva, no sentimentaloide, que se siente por un pasado ideal que se fue, para no volver jamás.

Por último, se buscó identificar la relación de los participantes con las expresiones "retro" y "cultura retro", cuyo empleo han puesto de moda la mercadotecnia y la industria mediática. Para los participantes de este estudio, el consumo de música retro les provee tranquilidad y confianza, pero sobre todo seguridad ontológica, porque la música de su generación le hace sentirse acogido respecto a los peligros y riesgos del mundo en que se vive hoy en día, sin la necesidad o la obsesión de querer regresar en el tiempo. La nostalgia que siente al escuchar sus canciones favoritas le hacen recordar el ayer, pero no para instalarse ahí perpetuamente, sino para reflexionar acerca de los valores del pasado reciente y poder darle sentido a su posición social vigente. Es solamente una manera efectiva de afianzarse de algo seguro y confiable en medio de la "turbulencia" que representa el tiempo actual.

Finalmente, la nostalgia posmoderna se construye como una manera de asimilar los errores pretéritos, con el fin de reconocer las causas que originaron los problemas del presente, pues, en general, todos los informantes mostraron una profunda preocupación y un cierto temor acerca del futuro incierto a donde van encaminándose las nuevas generaciones, las de sus propios hijos.

\section{REFERENCIAS BIBLIOGRÁFICAS}

Assmann, J. (1988/1995). Collective memory and cultural identity. New German Critique, 65, 125-133. http://dx.doi.org/10.2307/488538

Bauman, Z. (2017). Retrotopia. Cambridge, UK: Polity.

Berruga, L. (2015). La memoria nostálgica a través de Internet y de las Historias de vida. Historia y Comunicación Social, 20(2), 391-411. http://dx.doi.org/10.5209/rev HICS.2015.v20.n2.51390

Beck, U. (1998). Teoría de la sociedad del riesgo. En J. Beriain (comp.), Las consecuencias perversas de la modernidad (pp. 35-56). Barcelona: Anthropos.

Corsten, M. (1999). The time of generations. Time \& Society, 8(2), 249-272. https://doi.org/10.1177\%2F0961463X99008002003 
Davis, F. (1977). Nostalgia, identity and the current nostalgia wave. The Journal of Popular Culture, 11(2), 414-424.

Davis, F. (1979). Yearning for Yesterday: A Sociology of Nostalgia. Nueva York, EUA: Free Press.

Davis, F. (1981). Contemporary nostalgia and the mass media. En E. Katz y S. Tamás, Mass media and social change (pp. 219-230). Thousand Oaks, EUA: Sage.

De la Peza, C. (2001). El bolero y la educación sentimental en México. México, D.F.: Universidad Autónoma Metropolitana-Miguel Ángel Porrúa.

De la Peza, C. (2014). El rock mexicano. Un espacio en disputa. México: UAM-Tintable.

Echeverría, M. y Karam, T. (2014). La mediación simbólico regional y generacional en la recepción de la música vernácula. Estudios sobre las culturas contemporáneas, XX(39), 41-68.

Eyerman, R. y Turner, B.S. (1998). Outline of a theory of generations. European Journal of Social Theory, 1(1), 91-106. https://doi.org/10.1177\%2F136843198001001007

García, D. (2014). Mayoría de los habitantes de NL son de clase media. Milenio (diario online). Recuperado de http://www.milenio.com/negocios/mayoria-de-los-habitantesen-nl-son-de-clase-media

Ghiardo, F. (2004). Generaciones y juventud: una relectura de Mannheim y Ortega y Gasset. Última década, 20, 11-46.

https://scielo.conicyt.cl/pdf/udecada/v12n20/art02.pdf

Giddens, A. (1990). The consequences of Modernity. Stanford, EUA: Stanford University Press.

Giddens, A. (1991/2000). Modernidad e identidad del yo. El yo y la sociedad en la época contemporánea. Barcelona: Península.

Grainge, P. (2002). Monochrome memories: Nostalgia and style in retro America. Westport, EUA: Praeger.

Guffey, E. E. (2006). Retro: The culture of revival. Londres: Reaktion Books.

Habermas, J. (1981/1987). Teoría de la acción comunicativa. Buenos Aires: Taurus.

Hall, S. (1992/2003). The question of cultural identity. En S. Hall, D. Held y T. McGrew (eds.), Modernity and its futures. Understanding modern societies. An introduction book (pp. 273-326). Cambridge, Reino Unido: Blackwell.

Hall, S. (1996). Introduction: Who needs 'identity’? En S. Hall y P. du Gay (eds.), Questions of cultural identity (pp. 1-17). Londres: Sage. 
Howe, N. y Strauss, W. (1991). Generations: The History of America's future. Nueva York, EUA: Perennial.

Kiley, D. (1983). The Peter Pan síndrome: men who have never grown up. Nueva York, EUA: Dodd, Mead and Company.

Lull, J. (1985). On the communicative properties of music, Communication Research, 12, 363-372. https://doi.org/10.1177\%2F009365085012003008

Lull, J. (1992). Popular Music and Communication. Londres: Sage.

Nora, P. (1989). Between memory and history: Les lieux de memoire. Representations, 26, 7-24. http://www.jstor.org/stable/2928520?origin=JSTOR-pdf

Solzhenitsyn, A. (1993). The relentless cult of novelty and how it wrecked the century. New York Times Book Review, 49235, 3-4.

Stipp, H. (1990). Musical demographics: The strong impact of age on music preferences affects all kinds of business. American Demographics, 12, 48-49.

Zerubavel, E. (1996). Social memories: Steps to a Sociology of the past. Qualitative Sociology, 19(3), 283-299. https://doi.org/10.1007/BF02393273

Zerubavel, E. (2003). Time maps. Collective memory and the social shape of past. Chicago, EUA: The University of Chicago Press.

RAEIC, Revista de la Asociación Española de Investigación de la Comunicación vol. 6, núm. 11 (2019), 224-245 